\title{
A política agrícola na União Europeia e no Brasil: uma análise comparada de seus efeitos sobre a pluriatividade das famílias rurais
}

\author{
Carlos Alves do Nascimento*
}

\begin{abstract}
RESUMO - O artigo defende que a literatura europeia e brasileira, que aborda o tema da pluriatividade das famílias rurais, negligencia um elemento importante e decisivo, determinante do crescimento de casos de pluriatividade. Trata-se da política agrícola apoiando amplamente a permanência de pequenos produtores rurais familiares a alguma atividade agropecuária. Não considerar a política agrícola nas análises sobre a pluriatividade, como é o caso da referida literatura, dificulta entender, por exemplo, por que no Sul do Brasil, região na qual estariam reunidas todas as condições para o crescimento da pluriatividade, esta, ao contrário, apresentou redução anual significativa.
\end{abstract}

Palavras-chave: Pluriatividade. Política Agrícola. União Europeia. Brasil.

\section{INTRODUÇÃO}

O presente texto pretende comparar a política agrícola no Brasil com a Política Agrícola Comum (PAC) da União Europeia (UE), centrando a argumentação em um tema que se desenvolveu ali a partir da década de 1980 chegando ao Brasil em meados da década de 1990. Trata-se da pluriatividade, um termo que se refere a unidades familiares que combinam entre seus membros ocupações agrícolas e ocupações não-agrícolas - famílias pluriativas. Objetiva-se destacar a diferença entre os efeitos da PAC da UE e os da política agrícola brasileira sobre a pluriatividade dos agricultores familiares rurais. Procurar-se-á argumentar que a PAC contribui para o crescimento de casos de famílias pluriativas, enquanto que no Brasil a política agrícola, historicamente, contribuiu de forma negativa para a pluriatividade.

No que respeita ao Brasil, a análise restringir-se-á à região Sul porque esta região, além de ser de longe a segunda maior detentora da agricultura familiar nacional - depois da região Nordeste -, é a região que mais aprofundou o processo de modernização das estruturas produtivas no campo (NASCIMENTO, 2007).

Para cumprir o objetivo proposto, o texto ficou estruturado em mais quatro seções, além desta introdução. Na próxima seção apresentam-se brevemente alguns dados sobre a pluriatividade na UE e no Sul do Brasil com o intuito de embasar as argumentações a respeito das divergências que serão destacadas entre a política agrícola do Brasil e a da UE, dispostas na terceira seção, e a defesa, na quarta seção, de que a perspectiva de crescimento da

\footnotetext{
* Doutor em Economia Aplicada pela UNICAMP, Professor Adjunto do IE/UFU. Endereço eletrônico: can@ie.ufu.br.
} 
pluriatividade está condicionada ao apoio público, particularmente aos pequenos produtores agropecuários familiares. Por fim, a última seção apresentará as considerações finais.

\section{A PLURIATIVIDADE NO SUL DO BRASIL E NA UNIÃO EUROPEIA}

Entre fins da década de 1980 e início dos anos 1990, pesquisadores europeus empreenderam uma grande pesquisa (Arkleton Trust Project) com o objetivo, entre outros, de investigação do conjunto das fontes (agrícolas e não agrícolas) de renda e ocupação das unidades familiares rurais. O resultado da pesquisa do Arkleton Trust (1992) em relação à evolução da pluriatividade no período da sua investigação (1987 a 1991) aponta para a consolidação dessa cultura no interior dos domicílios agrícolas da antiga Comunidade Econômica Europeia (CEE), a ponto de o Relatório afirmar que a "pluriatividade é um fenômeno estável, sendo que 63\% dos estabelecimentos possui certa proporção da força de trabalho engajada na pluriatividade" ${ }^{27}$. Esta afirmação está baseada na Tabela 1. Pode-se ver

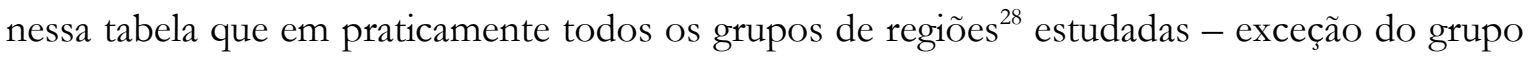
B2 (embora este fosse o grupo com maior porcentagem de estabelecimentos pluriativos) -, houve um crescimento do número de estabelecimentos pluriativos no período analisado. Pode-se perceber também que, diferentemente da evolução da pluriatividade, os estabelecimentos com mais de $95 \%$ da mão-de-obra ocupada exclusivamente na agricultura apresentam, em todos os grupos de regiões, taxas negativas de crescimento - novamente, a exceção foi o grupo B2.

TABELA 1 - REPARTIÇÃO (\%) DOS ESTABELECIMENTOS AGRÍCOLAS EM FUNÇÃO DA ESTRUTURA DE RENDA E VARIAÇÃO ENTRE 1987 E 1991, POR GRUPOS DE REGIÕES DE ESTUDO.

\begin{tabular}{l|c|c|c|c|c|c|c|c}
\hline \multirow{2}{*}{$\begin{array}{c}\text { Região de } \\
\text { estudo }\end{array}$} & \multicolumn{4}{|c|}{ Monoatividade (> 95\% da mão-de-obra ocupada em) } & \multicolumn{2}{c}{ Pluriatividade } \\
\cline { 2 - 10 } & \multicolumn{2}{|c|}{ Agricultura } & \multicolumn{1}{c}{ Para-agricultura } & \multicolumn{2}{c}{ Trabalho no exterior } & \multicolumn{2}{c}{$\mathbf{1 9 8 9}$} \\
\cline { 2 - 10 } & $\mathbf{1 9 8 7}$ & $\mathbf{1 9 9 1}$ & $\mathbf{1 9 8 7}$ & $\mathbf{1 9 9 1}$ & $\mathbf{1 9 8 7}$ & $\mathbf{1 9 9 1}$ & $\mathbf{1 9 8 7}$ & $\mathbf{1 9 9 1}$ \\
\hline Grupo A & 43,8 & $-6,6$ & 0,1 & - & 0,1 & 2,4 & 56 & 4,2 \\
\hline Grupo B1 & 47 & $-1,7$ & 0,1 & 0,4 & 0,5 & 0,6 & 52,4 & 0,7 \\
\hline Grupo B2 & 13,1 & 4,3 & 0,4 & 0,2 & 0,3 & 3,3 & 86,3 & $-7,8$ \\
\hline Grupo C1 & 44,7 & $-3,4$ & 0,1 & 0,3 & 0,4 & 2,4 & 54,8 & 0,7 \\
\hline Grupo C2 & 20,4 & $-3,8$ & 0 & 0,3 & 0,2 & 0,6 & 79,4 & 2,9 \\
\hline Total & 36,9 & $-3,1$ & 0,1 & 0,2 & 0,3 & 1,8 & 62,7 & 1,1 \\
\hline
\end{tabular}

Fonte: Arkleton Trust (1992: 225).

Os dados sobre a pluriatividade no Sul do Brasil referem-se aos tipos de familias classificados pela posição na ocupação dos membros da família (empregador, conta-própria,

\footnotetext{
27 ARKLETON TRUST (1992, p. 254).

28 A pesquisa do Arkleton Trust abrangeu várias regiões no interior da CEE, as quais foram repartidas em 5 grupos de estudo. Para quem tiver interesse, a descrição e características completas dos referidos grupos encontram-se no Capítulo 3 do Relatório do Arkleton Trust (1992, pp. 64 a 82).
}

68 
assalariado, não ocupado) e, em seguida, pelo ramo de atividade em que estão inseridos (agrícola, não agrícola, pluriativo) ${ }^{29}$. O foco recairá apenas nas famílias de conta-próprias e de assalariados porque ambas compreendiam mais de $80,0 \%$ do total de famílias rurais não metropolitanas agropecuárias ${ }^{30}$ sulinas, nos períodos analisados. Construiu-se essa tipologia a partir dos microdados da Pesquisa Nacional por Amostra de Domicílios - PNAD, do IBGE.

No Sul do Brasil, como pode ser visto na Tabela 2, o número de famílias contapróprias pluriativas reduziu-se a uma taxa média anual de 2,2\%, assim como também apresentou taxa de crescimento negativa (2,9 \% a.a.) o número de famílias conta-próprias agrícolas, no período de 1992 a 1999. No sentido contrário, a Tabela 2 mostra o forte crescimento positivo do número de famílias não agrícolas (conta-próprias, 9,4\% a.a., e assalariadas, $7,6 \%$ a.a.).

Observe-se que ambos os tipos de agricultura familiar (famílias de conta-próprias agrícolas e pluriativas) no Sul do Brasil sofreram uma redução ao longo de toda a década de 1990, sem que a pluriatividade pudesse conter esse declínio, demonstrando o não cumprimento da função, que lhe é atribuída pela literatura, de sustentáculo da agricultura familiar. Destaca-se novamente que, por outro lado, o que cresceu vigorosamente foi o conjunto das famílias não agrícolas. Esses dados darão suporte à discussão tecida na penúltima seção.

A Tabela 3, por sua vez, mostra que no período de 2001 a 2005 o número de famílias de conta-próprias pluriativas sulinas não mais exibiu trajetória declinante, permanecendo estabilizada (do ponto de vista estatístico). Contudo, continuou em declínio semelhante à década de 1990 - o número de famílias de conta-próprias estritamente agrícolas (-3,0\% a.a.). O conjunto de famílias de assalariados é que apresentou taxa de crescimento positiva $(2,8 \%$ a.a.). A hipótese explicativa para a estabilidade da pluriatividade nesse último período é que - conforme será melhor compreendido depois da exposição dos argumentos das seções seguintes - de alguma forma houve mudança na política agrícola no Brasil (vide a expansão da cobertura do $\operatorname{PRONAF}^{31}$ ) no sentido de um maior apoio aos pequenos produtores rurais familiares.

\footnotetext{
${ }^{29}$ Ver a metodologia de construção dessa tipologia em NASCIMENTO (2008).

30 As áreas censitárias consideradas rurais pela Pesquisa Nacional por Amostra de Domicílios - PNAD compreendem cinco tipos: 1) área rural de extensão urbana; 2) aglomerado rural (povoado); 3) aglomerado rural núcleo; 4) aglomerado rural (outros); 5) área rural exclusive aglomerado rural. O rural agropecuário, portanto, é constituído pela soma dos números 3 e 5. A idéia de separar o rural agropecuário é tentar reconstruir os espaços considerados predominantemente agrícolas que são por excelência espaços apropriados por um único dono (público ou privado).

${ }^{31}$ FARIA (2006).
} 
TABELA 2 - EVOLUÇÃO QUANTITATIVA DOS TIPOS DE FAMÍLIAS EXTENSAS SEGUNDO O LOCAL DE DOMICÍLIO: SUL, 1992/99. (1000 FAMÍLIAS)

\begin{tabular}{|c|c|c|}
\hline \multirow{2}{*}{$\begin{array}{l}\text { LOCAL DOMICÍLIO / } \\
\text { TIPO DE FAMÍLIA }\end{array}$} & \multirow{2}{*}{$\begin{array}{c}\text { Mil fam } \\
1999\end{array}$} & \multirow{2}{*}{$\begin{array}{r}\text { tx cresc. } \\
\text { (\% aa.) } \\
1992 / 99^{a}\end{array}$} \\
\hline & & \\
\hline \multicolumn{3}{|l|}{ NÃO METROPOLITANO } \\
\hline \multicolumn{3}{|l|}{ RURAL AGROPECUÁRIO } \\
\hline Conta-Própria & 671 & $-2,0 * \star \star$ \\
\hline Agrícola & 467 & $-2,9 \star \star \star$ \\
\hline Pluriativo & 138 & $-2,2 * *$ \\
\hline Não-agrícola & 67 & $9,4^{* \star \star}$ \\
\hline Assalariados & 428 & $3,2 * \star \star$ \\
\hline Agrícola & 185 & 0,5 \\
\hline Pluriativo & 42 & $-1,0$ \\
\hline Não-agrícola & 201 & $7,6^{\star \star *}$ \\
\hline
\end{tabular}

Nota: exclusive as famílias sem declaração de renda e tipos de familia com menos de 6 observações

a) estimativa do coeficiente de uma regressão log-linear contra o tempo. Neste caso, o teste t indica a existência ou não de uma tendência nos dados. ${ }^{* \star *}$, **, * significam respectivamente 5\%, 10\% e 20\%.

Fonte: Microdados da PNAD - Tabulações Especiais do Projeto Rurbano.

TABELA 3 - EVOLUÇÃO QUANTITATIVA DOS TIPOS DE FAMÍLIAS EXTENSAS SEGUNDO O LOCAL DE DOMICÍLIO: SUL, 2001/2005. (1000 FAMÍLIAS)

\begin{tabular}{|c|c|c|}
\hline \multirow{2}{*}{$\begin{array}{l}\text { LOCAL DOMICÍLIO / } \\
\text { TIPO DE FAMÍLIA }\end{array}$} & \multirow{2}{*}{$\begin{array}{c}\text { Mil fam } \\
2005\end{array}$} & \multirow{2}{*}{$\begin{array}{c}\begin{array}{c}\text { tx cresc. } \\
\text { (\% aa.) }\end{array} \\
2001 / 2005^{a}\end{array}$} \\
\hline & & \\
\hline \multicolumn{3}{|l|}{ NÃO METROPOLITANO } \\
\hline \multicolumn{3}{|l|}{ RURAL AGROPECUÁRIO } \\
\hline Conta-Própria & 669 & $-1,0$ \\
\hline Agrícola & 446 & $-3,0 * * *$ \\
\hline Pluriativo & 170 & 3,9 \\
\hline Não-agrícola & 53 & 2,1 \\
\hline Assalariados & 363 & $2,8^{* \star *}$ \\
\hline Agrícola & 154 & 2,1 \\
\hline Pluriativo & 46 & 0,9 \\
\hline Não-agrícola & 164 & 4,2 \\
\hline
\end{tabular}

Nota: exclusive as famílias sem declaração de renda e tipos de familia com menos de 6 observações

a) estimativa do coeficiente de uma regressão log-linear contra o tempo. Neste caso, o teste t indica a existência ou não de uma tendência nos dados. ***, **, * significam respectivamente 5\%, 10\% e $20 \%$.

Fonte: Microdados da PNAD - Tabulações Especiais do Projeto Rurbano.

\section{A POLÍTICA AGRÍCOLA NO BRASIL E NA UNIÃO EUROPÉIA}

A Política Agrícola Comum (PAC) da União Europeia (UE) é contemporânea da política de modernização intensiva da agricultura brasileira. Ambas datam da década de 1960. Tanto a PAC quanto a política agrícola de modernização brasileira ${ }^{32}$ tinham como um de seus objetivos centrais o aprofundamento da dinâmica capitalista no meio rural, com objetivo claro de elevar a produção e a produtividade agropecuárias, constituir mercado para indústria de máquinas e insumos, além de procurar cumprir as clássicas funções de fornecimento de mãode-obra para a indústria, baratear o custo de reprodução da força de trabalho urbana, reduzir o custo da matéria-prima industrial de origem agrícola. Por outro lado, tinham motivações distintas. A PAC era motivada pela vontade das sociedades, que formaram inicialmente a

\footnotetext{
${ }^{32}$ Essa política integrava um conjunto de sistemas: financeiro, de pesquisa e de extensão rural, todos voltados especificamente para a agropecuária.
} 
antiga Comunidade Econômica Europeia $(\mathrm{CEE})^{33}$, de tornarem-se autossuficientes na produção agropecuária e de garantir sua segurança alimentar - além de que seria parte importante no esforço para assegurar o pleno emprego (preocupação política central do segundo pós-guerra). A política de modernização da agricultura brasileira, por sua vez, tinha como motivação maior fazer frente à histórica restrição externa ao crescimento econômico do país - uma vez que a indústria aqui montada não era competitiva no mercado internacional ${ }^{34}$.

Outra importante diferença entre as duas políticas - que é o que mais interessa ressaltar - reside no fato de que a PAC, diferentemente da política agrícola modernizadora brasileira, ao mesmo tempo em que envidou esforços para elevar a produtividade das atividades agropecuárias, assegurou, por outro lado, mecanismos ${ }^{35}$ que atenuavam os potenciais efeitos negativos da modernização agrícola sobre os pequenos produtores familiares menos aptos a se ajustarem às novas exigências modernizantes - exigências que acirrariam cada vez mais a concorrência entre os diferentes capitais agrícolas individuais. $\mathrm{Ou}$ seja, pode parecer paradoxal, mas a PAC foi exitosa em, a um só tempo, elevar a produtividade da agropecuária e controlar a redução da PEA agrícola, contendo o ímpeto do êxodo rural. E essa política foi bem sucedida nesse aspecto justamente pela preocupação efetiva que teve em atender não apenas aos interesses de grandes produtores, mas também atender ao conjunto dos pequenos produtores, considerados inaptos ao mercado ${ }^{36}$.

Para sustentar a afirmação anterior, observe na Tabela 4 que a redução da força de trabalho agrícola nos países da CEE não teve muita diferença entre os dois períodos comparados (pré-PAC, antes de 1962, e pós-PAC, a partir de 1962). Isto sugere que o efeito negativo do aumento da produtividade do trabalho sobre a população agrícola foi contido pela própria política que impulsionou a produtividade: a PAC. Os dados da Tabela 4 sugerem que sem a política de preços administrados e a Preferência Comunitária - políticas medulares da PAC - a queda do emprego agrícola poderia ter sido mais intensa (ver detalhes em NASCIMENTO, 2008). Esses dois instrumentos de política preservaram numerosas

\footnotetext{
33 Os primeiros seis países que formaram a CEE foram Bélgica, França, Itália, Holanda, Luxemburgo e Alemanha. Em 1973, aderiram também: Dinamarca, Irlanda e Reino Unido. Em 1981 foi a vez da Grécia e, em 1986, da Espanha e Portugal. Somente em 1992 passaram a fazer parte da Comunidade Áustria, Suécia e Finlândia. Vários países do Leste Europeu foram incorporados à CEE na década de 1990.

${ }^{34}$ Furtado (2000).

35 A Política de Preços Administrados e o Princípio da Preferência Comunitária. A garantia da preferência Comunitária implicava tanto a realização de toda a produção de todos os produtores como também assegurava a todos os produtores a proteção da competição dos produtos estrangeiros.

36 Por falta de espaço, remeto o leitor a outro trabalho, Nascimento (2008), no qual constam fartos elementos que sustentam essa afirmação. Nesse livro apresenta-se também uma análise sobre a pluriatividade no Nordeste do Brasil.
} 
pequenas unidades familiares agropecuárias: fator decisivo para a proliferação de casos de pluriatividade (conforme reflexão mais detalhada na seção seguinte).

TABELA 4: TAXAS DE CRESCIMENTO DA POPULAÇÃO AGRÍCOLA POR PAÍSES DA COMUNIDADE ECONÔMICA EUROPÉIA.

\begin{tabular}{|c|c|c|c|}
\hline PAÍSES & $1930-1947$ & 1947-1961 & $1961-1970$ \\
\hline Bélgica & $-34,2$ & $-40,2$ & $-30,7$ \\
\hline & 1946-1954 & 1954-1962 & 1962-1970 \\
\hline França & $-30,6$ & $-24,8$ & $-32,2$ \\
\hline & 1950-1961 & \multicolumn{2}{|c|}{ 1961-1970 } \\
\hline Alemanha & $-30,2$ & \multicolumn{2}{|c|}{$-36,9$} \\
\hline & 1951-1961 & \multicolumn{2}{|c|}{$1961-1970$} \\
\hline Itália & $-31,5$ & \multicolumn{2}{|c|}{$-31,4$} \\
\hline & 1947-1960 & \multicolumn{2}{|c|}{ 1960-1970 } \\
\hline Holanda & $-40,2$ & \multicolumn{2}{|c|}{$-35,3$} \\
\hline
\end{tabular}

Fonte: Adaptado de Cipolla (1976: 657-665).

No Brasil, como não existe esse tipo de preocupação por parte das velhas e novas políticas voltadas para o setor, a pluriatividade é uma cultura a ser constantemente esvaída pelo progresso econômico, conduzido nos moldes da "modernização dolorosa", em simultâneo às crises pelas quais passam constantemente os pequenos produtores desprovidos dos aportes públicos para enfrentá-las. Não obstante o processo de "modernização dolorosa" da agricultura brasileira - assentado no modelo de busca desenfreada da elevação da produtividade - ter, como uma de suas consequências, criado certas condições ${ }^{38}$ para a proliferação da pluriatividade, por outro lado, foram criadas também, paralelamente, as condições para a retração contínua da pluriatividade na região, ao longo do tempo. Para se entender essa afirmação cumpre recordar que a modernização da agricultura no Brasil, nos anos 60 e 70, ocorrida nos moldes da modernização dolorosa, cumpria duplo objetivo: por um lado, atender às necessidades internas do desenvolvimento capitalista a partir dos anos 50; por outro lado, reforçava o seu desiderato histórico de ser o setor com grande peso no financiamento das necessidades nacionais de importação.

Isso significa dizer que a agropecuária, no Brasil, jamais foi vista pelas políticas públicas destinadas a ela como um espaço também daqueles produtores que não têm a capacidade de se moldar às exigências de produtividade e fazer frente aos desígnios históricos do setor, conforme posto acima. Para esse segmento de produtores, que não conseguem atingir o perfil do "verdadeiro agricultor", resta se ocupar plenamente em ocupações rurais não agrícolas, ou continuarem perpetuamente marginalizados na sua relação com a terra, ou se tornarem definitivamente não ocupados.

\footnotetext{
${ }^{37}$ Termo cunhado por SILVA (1982).

38 Elevação da produtividade das explorações familiares modernizadas, liberando mão-de-obra familiar para se ocupar em outras atividades - não agrícolas ou agrícolas por assalariamento (em outros estabelecimentos).
} 
Nesses termos a pluriatividade fica comprometida à medida que os pequenos produtores familiares tendem a abandonar suas atividades agropecuárias, por incapacidade de mantê-las sem o apoio devido das políticas públicas. No Sul do Brasil, dada a forte exposição à concorrência externa dos anos 1990 - Mercosul e abertura comercial - combinada à falta (ou insuficiência) do referido apoio público, a pluriatividade declinou significativamente (Tabela 2). Nos anos 2000, em virtude de uma melhora nas condições macroeconômicas e maior aporte e abrangência do PRONAF, os dados da PNAD, relativos aos anos 2001 a 2005 (Tabela 3), refletem uma mudança da trajetória anterior, o que só confirma a argumentação central deste texto. Essa relação existente entre apoio público insuficiente e redução da pluriatividade (ou dificuldade para seu crescimento) será mais bem tratada na seção seguinte.

\section{O FUTURO DA PLURIATIVIDADE ESTÁ CONDICIONADO AO FUTURO DA PEQUENA AGRICULTURA FAMILIAR}

Antes de avançarmos nessa seção, deve ficar claro que as famílias pluriativas conciliam entre seus membros atividades agrícolas com atividades não agrícolas. Não existe pluriatividade sem o vínculo a uma atividade agrícola. A literatura que trata desse tema não considera pluriatividade apenas com atividades não agrícolas, por mais diversas que sejam as atividades não agrícolas que os membros de uma família estejam ocupados. Ou seja, a pluriatividade é constituída por dois vetores de determinação: um "lado agrícola" e um "lado não agrícola". $\mathrm{Na}$ falta de um deles, a pluriatividade deixa de existir.

O argumento da política pública - central neste texto - não exclui as características ${ }^{39}$ apontadas pela literatura, no caso da União Europeia (e por autores brasileiros que também identificam características similares no Sul do Brasil), como determinantes do crescimento da pluriatividade (da conversão de famílias de agricultores em famílias pluriativas). Pelo contrário, o argumento da política pública considera tais características. Apenas as considera insuficientes para explicar a evolução da pluriatividade, seja na UE, seja no Sul do Brasil. Dizer que são insuficientes não quer dizer que não sejam importantes, em absoluto. A questão é que tais características se restringem ao "lado não agrícola" dos determinantes da pluriatividade. E a evolução da pluriatividade não se explica plenamente só pelo "ado não agrícola". Faz-se necessário pensar o "lado agrícola" (da combinação "agrícola com não

\footnotetext{
39 Características de redes urbanas que circundam áreas rurais e que têm potencial de ofertar oportunidades de ocupação em atividades econômicas não agrícolas. Por exemplo, regiões com malhas de cidades e povoados que formam territórios e núcleos urbanos ampliados, integrados por redes de estradas principais e secundárias, dotada de ativos históricos e culturais que atraem milhões de pessoas todos os anos etc. Ou seja, esse constitui o "lado não agrícola" determinante da pluriatividade.
} 
agrícola", própria da pluriatividade), e aqui repousa o diferencial dos argumentos deste texto. Para pensar o "lado agrícola", que diz respeito à permanência ou o abandono das atividades agrícolas, especialmente por parte dos pequenos produtores familiares, importa considerar o papel do Estado, das políticas públicas.

Ou seja, dizer que o papel do Estado é decisivo significa, fundamentalmente, dizer que numa região como o Sul do Brasil - ou a UE - que tem o "lado não agrícola" bem desenvolvido, o qual poderia, em tese, estimular a pluriatividade, se não houver estímulos também pelo "lado agrícola" - particularmente para evitar que os pequenos produtores, historicamente alijados do apoio público, abandonem as atividades agrícolas -, não haverá perspectivas de crescimento de casos de pluriatividade. Poderá, sim, haver mais perspectivas de crescimento de casos de famílias rurais não agrícolas. E o que pode estimular, apoiar, o "lado agrícola" (de pequenos produtores), senão o Estado, as políticas públicas? Sem o apoio do Estado, como os pequenos produtores agrícolas familiares manterão suas atividades agrícolas? E sem a atividade agrícola, como existirá (e aumentará) a pluriatividade? A pluriatividade não existe só com o elo não agrícola.

Sem esse apoio do Estado, e residindo em áreas rurais de redes urbanas dinâmicas, seja no Sul do Brasil, seja na UE, a tendência, a perspectiva, é de as famílias de pequenos produtores agrícolas se converterem não em famílias rurais pluriativas, mas em famílias rurais não agrícolas (ver Tabela 2). Na UE, essa conversão se dá mais no sentido da pluriatividade (razão pela qual o Relatório do Arkleton Trust, 1992, registra crescimento da pluriatividade na $\mathrm{CEE}$, hoje UE), justamente porque a $\mathrm{PAC}$ apoia os pequenos produtores rurais familiares a preservarem algum vínculo com alguma atividade agrícola (não importando a natureza desta, se para o mercado ou não). Somam-se a esse apoio as características apontadas pela literatura (nota 14), e o resultado é mais pluriatividade. Sem o referido apoio, as características apontadas pela literatura propiciam a conversão das famílias agrícolas em famílias não agrícolas, mas não em pluriatividade (pelo menos não do ponto de vista de uma perspectiva de crescimento dela).

Isso é o que a literatura especializada - importada da UE - não considerou. Por quê? Porque o problema inerente a essa literatura - e isso é o que induziu à distorção no Brasil está em associar a ampliação da pluriatividade aos estímulos ao fomento de atividades não agrícolas para as populações rurais, ao fomento a ações voltadas para o desenvolvimento rural, ações que fortalecem, potencializam, todos os ativos histórico-culturais nas áreas rurais e ao redor delas. 
Ora, a literatura da UE sobre a pluriatividade não considera a PAC como determinante (pelo 'lado agrícola') da pluriatividade justamente porque a PAC crion - esse é o verbo mais apropriado - uma situação relativamente estável, do ponto de vista da renda familiar, para inúmeros pequenos produtores familiares, de modo que a literatura europeia (e aí a brasileira a segue) associa a pluriatividade fundamental e exclusivamente às ocupações rurais não agrícolas - ORNAs (o "lado não agrícola"), as quais são derivadas de: i) entornos rurais (redes urbanas regionais/territoriais) com economias dinâmicas, ofertantes de ORNAs; ii) estratégias familiares de diversificação de atividades não agrícolas (ORNAs), não necessariamente de sobrevivência: a busca por inserção em novos mercados em resposta às dificuldades financeiras; uma tentativa de reduzir os riscos da atividade agrícola; ou ainda uma resposta às oportunidades surgidas nos mercados de trabalho e de produtos; iii) as migrações de parentes/familiares que se ocuparam em ORNAs, as quais viabilizarão remessas de rendas não agrícolas para os estabelecimentos; iv) as infra-estruturas das economias locais, os recursos naturais, culturais e humanos são também aspectos a serem levados em conta ao analisar o maior ou menor êxito da pluriatividade em um determinado território. (REIS et al., 1990; MARSDEN, 1990; FULLER, 1990; BRUN e FULLER, 1991; ARKLETON TRUST, 1992; OECD, 1998). Os trabalhos desenvolvidos no Brasil não fogem a essa abordagem (KAGEYAMA, 1998; SCHNEIDER, 2003; ANJOS, 2003; entre outros).

Perceba-se que a ênfase dessa literatura especializada recai no "lado não agrícola" da combinação "agrícola com não agrícola" (própria da pluriatividade). Mas, perceba-se também que, não obstante isso, a associação feita não é com o que realmente dever-se-ia associar: as famílias rurais não agrícolas, mas com a pluriatividade - supostamente para explicar o sucesso da pluriatividade na UE (e, no caso brasileiro, para explicar que o Sul tem todas as condições para o crescimento da pluriatividade).

Note-se ainda que o "lado agrícola", nessa concepção presente (e que lhe é central) na referida literatura, perde importância. Mas aqui é o ponto em que o presente artigo é importante, porque mostra que não somente o 'lado não agrícola' deve ser fomentado, mas também o "lado agrícola" deve ser protegido, valorizado, evitando o abandono das atividades agrícolas pelos pequenos produtores. Porque o lado não agrícola, quanto mais dinâmico, e sem políticas que valorizem os pequenos produtores agrícolas, pode viabilizar o crescimento de famílias não agrícolas, e não de famílias pluriativas $^{40}$. E quem é o responsável pelo apoio aos

\footnotetext{
${ }^{40}$ Com isso não se está querendo contrapor - em termos de juízo de valor - um tipo de família a outro, se um é melhor do que outro. Apenas se está argumentando sobre o que pode favorecer o crescimento de um e de outro tipo familiar.
} 
pequenos produtores agrícolas familiares, na UE, senão a PAC? Sem a PAC, Nascimento (2008) mostra que numerosos pequenos produtores familiares da UE não existiriam e junto com eles não existiria o sucesso de casos de pluriatividade, porque a PAC viabiliza a permanência dos agricultores "ineficientes" - do ponto de vista da sua produção para o mercado - ligados a uma atividade agrícola (mesmo que seja para não produzirem nada para o mercado, mas somente para "preservar a natureza”).

Além disso, existem na UE as políticas estruturais de desenvolvimento rural que fomentam uma série de outras formas de ocupação para as populações rurais, de tal sorte que o agricultor se beneficia, por um lado, de ajudas diretas do Estado (não se trata de crédito, mas ajudas diretas "a fundo perdido"), via PAC, para "preservar a natureza", sem produzir para o mercado, e, por outro lado, o entorno rural é dinâmico em ofertar outras formas de ocupação e geração de renda. O resultado desse duplo vetor de ações é que a família desse produtor torna-se pluriativa. Esse é um resultado "natural"? Ou se deve àquelas características apontadas pela literatura (o "lado não agrícola"), de um lado, e à PAC (o "lado agrícola") pagando para milhares ${ }^{41}$ de pequenos produtores familiares manterem-se com algum vínculo a uma atividade agrícola (não importando a natureza desta, se para o mercado ou apenas para preservar o meio ambiente)?

\section{CONSIDERAÇÕES FINAIS}

Nascimento (2008) apresenta dados relativos à reforma da PAC em 1992, cujo teor reitera a perspectiva de amplo apoio e preservação da estrutura agrária familiar, apresentando número, até 2001, relativos aos gastos, crescentes, com esse apoio. Estrada e Fernandez (2007) mostram que a PAC paulatinamente seguiu - ao longo das reformas dos anos 2000 metamorfoseando-se em direção à noção de multifuncionalidade da agricultura européia, cuja tendência fundamental é reafirmação do princípio originário da PAC de sustentação do largo espectro de pequenos produtores familiares, que sem essa política iriam agravar mais ainda as condições críticas do mundo do trabalho, urbano e rural, europeu.

Quanto ao Brasil, defende-se a ampliação dos instrumentos e aportes de recursos das políticas destinadas à agricultura familiar - mais do que apostar tão-somente no fomento a ocupações rurais não agrícolas - como condição sine qua non para o crescimento do número de famílias rurais pluriativas - caso este se torne um dos objetivos dos formuladores de

\footnotetext{
${ }^{41}$ Milhares, segundo a literatura européia utilizada por Nascimento (2008).
} 
políticas para o meio rural. Os dados da PNAD dos anos 2000, comparativamente à década de 1990, dão uma mostra da justeza dessa tese.

\section{REFERÊNCIAS}

ARKLETON TRUST. Adaptation des Menages Agricoles en Europe Occidentale 19871991 - Rapport final du programme de recherche sur les structures et la pluriactivite des menages agricoles. Luxembourg, Commission Européenne, 1992.

BRUN, A. H.; FULLER, A. M. Farm Family Pluriactivity in Europe. Stratley: ARKLETON TRUST, 1992.

CIPOLLA, C. M. The fontana economic history: contemporary economies: parts one and two. Glasgow: William Collins Sons \& Co., 1976.

ESTRADA, E. M.; FERNANDEZ, F. E. G. La funcionalidad agrária y territorial: discursos y políticas sobre agricultura y desarrollo rural. Economia Ensaios, Uberlândia, v. 22, n. 1, jul./dez. 2007.

FARIA, F. F. Distribuição de crédito para agricultura familiar: um estudo do pronaf a partir de um indicador de desenvolvimento rural. Dissertação - Instituto de Economia, Universidade Federal de Uberlândia, 2006.

FULLER, A. M. From Part Time Farming to Pluriativity: a decade of change in rural Europe. Journal of Rural Studies, London, v. 6, n. 4, p. 361-373, 1990.

FURTADO, C. Introdução ao desenvolvimento: enfoque histórico-estrutural. São Paulo: Paz e Terra, 2000.

SILVA, J. G. da. A modernização dolorosa: estrutura agrária, fronteira agrícola e trabalhadores rurais no Brasil. Rio de Janeiro: Zahar Editores, 1982.

KAGEYAMA, A. Pluriatividade e ruralidade: aspectos metodológicos. Economia Aplicada, v. 2, n. 3, p. 515-551, jul./set. 1998.

MARSDEN, T. Towards the Political Economy or Pluriactividy. Journal of Rural Studies, London, v. 6, n. 4, p.375-382, 1990.

NASCIMENTO, C. A. Pluriatividade, Pobreza Rural e Políticas Públicas: uma análise compara entre Brasil e União Européia. Fortaleza: BNB, 2008. (BNB Tese e Dissertações, n. 11)

NASCIMENTO, C. A. Pluriatividade e Políticas Públicas: o caso do Sul do Brasil. Revista de Economia Política, v. 27, p. 452-471, 2007.

OECD. Agricultural Policy Reform and the Rural Economy in OECD Countries. Paris: OECD, 1998.

OLIVEIRA, F. A economia da dependência imperfeia. Rio de Janeiro: Graal, 1977.

REIS, J. et. al. How 'Rural' is Agricultural Pluriactivity? Journal of Rural Studies, Great Britain, v. 6, n. 4, p. 395-399, 1990.

ANJOS, F. S. dos. Agricultura familiar, pluriatividade e desenvolvimento rural no Sul do Brasil. Pelotas: EGUFPEL, 2003.

SCHNEIDER, S. Pluriatividade na agricultura familiar. Porto Alegre: Editora da UFRGS, 2003. 
